\title{
The Impact of a Home-Based Palliative Care Program in an Accountable Care Organization
}

\author{
Dana Lustbader, MD, FAAHPM, ${ }^{1}$ Mitchell Mudra, MBA, ${ }^{2}$ Carole Romano, BA, ${ }^{3}$ Ed Lukoski, BS, \\ Andy Chang, BS, James Mittelberger, MD, Terry Scherr, BS, and David Cooper, MD ${ }^{5}$
}

\begin{abstract}
Background: People with advanced illness usually want their healthcare where they live-at home-not in the hospital. Innovative models of palliative care that better meet the needs of seriously ill people at lower cost should be explored.

Objectives: We evaluated the impact of a home-based palliative care (HBPC) program implemented within an Accountable Care Organization (ACO) on cost and resource utilization.

Methods: This was a retrospective analysis to quantify cost savings associated with a HBPC program in a Medicare Shared Savings Program ACO where total cost of care is available. We studied 651 decedents; 82 enrolled in a HBPC program compared to 569 receiving usual care in three New York counties who died between October 1, 2014, and March 31, 2016. We also compared hospital admissions, ER visits, and hospice utilization rates in the final months of life.

Results: The cost per patient during the final three months of life was $\$ 12,000$ lower with HBPC than with usual care $(\$ 20,420$ vs. $\$ 32,420 ; p=0.0002)$; largely driven by a $35 \%$ reduction in Medicare Part A $(\$ 16,892$ vs. $\$ 26,171 ; p=0.0037)$. HBPC also resulted in a $37 \%$ reduction in Medicare Part B in the final three months of life compared to usual care $(\$ 3,114$ vs. $\$ 4,913 ; p=0.0008)$. Hospital admissions were reduced by $34 \%$ in the final month of life for patients enrolled in HBPC. The number of admissions per 1000 beneficiaries per year was 3073 with HBPC and 4640 with usual care $(p=0.0221)$. HBPC resulted in a $35 \%$ increased hospice enrollment rate $(p=0.0005)$ and a $240 \%$ increased median hospice length of stay compared to usual care (34 days vs. 10 days; $p<0.0001)$.

Conclusion: HBPC within an ACO was associated with significant cost savings, fewer hospitalizations, and increased hospice use in the final months of life.
\end{abstract}

\section{Introduction}

$\mathbf{T}$ HE SICKEST $5 \%$ OF patients in the United States account for $>50 \%$ of costs, with the largest portion spent in the final months of life, generally for inpatient care. ${ }^{1}$ Over the past decade, hospital-based palliative care teams have demonstrated improved outcomes and cost savings. ${ }^{2-4}$ To date, little has been reported on the economic impact of homebased palliative care (HBPC) programs. ${ }^{5}$ Home-based care is especially important since hospitals may accelerate functional decline for those with advanced illness. ${ }^{6}$ Many patients with chronic or terminal illness who might benefit from palliative care are excluded from the Medicare Hospice Benefit if they wish to continue certain medical treatments or have a multitude of chronic conditions but no single certifiable hospice diagnosis.

We describe a nurse and social work model of HBPC in the New York metropolitan area in the context of a Medicare

\footnotetext{
${ }^{1}$ Department of Palliative Care, ProHEALTH Care, Lake Success, New York.

${ }^{2}$ Optum Center for Palliative and Supportive Care, Eden Prairie, Minnesota.

${ }^{3}$ ProHEALTH Medical Management, An Optum Company, Lake Success, New York.

${ }^{4}$ Healthcare Analytics, OptumCare, Eden Prairie, Minnesota.

${ }^{5}$ ProHEALTH Care, Lake Success, New York.

Accepted August 20, 2016.
}

(C) Dana Lustbader, et al., 2016; Published by Mary Ann Liebert, Inc. This Open Access article is distributed under the terms of the Creative Commons Attribution Noncommercial License (http://creativecommons.org/licenses/by-nc/4.0/) which permits any noncommercial use, distribution, and reproduction in any medium, provided the original author(s) and the source are credited. 
Shared Savings Program (MSSP) Accountable Care Organization (ACO). The Center for Medicare and Medicaid Services (CMS) selected 434 provider organizations to participate in the MSSP, which serves 8 million beneficiaries nationwide. Our objective was to evaluate the cost savings and outcomes associated with HBPC in a Medicare fee for service ACO population where high-value care is rewarded.

\section{Clinical scenario}

Mrs. $M$ is an 87-year-old woman who lives alone in New York. Her husband died 22 years ago and her two sons live in California. She has advanced heart failure, renal insufficiency, atrial fibrillation, and spinal stenosis with three ER visits and one hospital admission in the past 12 months. She uses a walker with increasing difficulty leaving her home. Mrs. $M$ is in the ProHEALTH ACO but has not seen her primary care doctor recently, although she does see her cardiologist. She was identified as a high-risk patient from ACO Medicare claims data, so a member of ProHEALTH Care Support, a HBPC program, reached out to her. Upon enrollment, a nurse made house calls and coordinated private hire home health aides to assist her with bathing. Her medications were simplified by the HBPC physician following discussions with her other doctors from 16 pills to 6 pills per day and the blood thinner was stopped due to recent falls. Mrs. $M$ is tired of calling 911 and going to the hospital for shortness of breath and back pain where she feels "abandoned for hours in that dark ER hallway." The HBPC team started an opioid and bowel regimen to better manager her back pain. They also prescribed medications to have on hand for shortness of breath and provided medical guidance 24/7. She has not been to the ER since enrolling in HBPC four months ago.

\section{Methods}

\section{HBPC program}

ProHEALTH Care Support is a HBPC program within the department of palliative care at ProHEALTH Care, a large multispecialty physician practice with 900 providers in 200 locations throughout the New York metropolitan area, including 30 urgent care centers. The medical group does not own hospitals, home health agencies, or hospice programs and is focused primarily on outpatient care. The practice serves 1 million patients in a largely fee for service market. ProHEALTH is part of OptumCare, a large national healthcare delivery organization. The HBPC program was developed to manage high-need patients within the MSSP ACO Track 1 (e.g., shared savings only, no risk). Billing within an ACO is the same as any fee for service market, but if savings are generated compared to a baseline benchmark, the ACO shares in that savings with Medicare as long as certain quality indicators are achieved.

The HBPC team comprised six registered nurses, two social workers, two doctors, one data analyst, and three administrative staff. The providers have strong clinical skills in palliative care. Each nurse is responsible for 90 patients (from the MSSP ACO and other shared savings health plans) in collaboration with a social worker and palliative care physician. Each nurse makes about five home visits and five phone calls per day. Most patients get at least one house call and two telephone calls per month with additional outreach from team members as needed. The team engages in serious illness conversations about goals of care ${ }^{7}$ with patients over time with documentation of treatment preferences (e.g., DNR, do not resuscitate orders) using the New York State Medical Orders for Life Sustaining Treatment (MOLST) form. There are twice-weekly in person team meetings and a one-hour weekly one-to-one with the nurse, social worker, and palliative care physician to review the nurse caseload in detail. During these one-to-ones, the HBPC physician may reach out to the patient's other physicians to coordinate care while keeping them informed.

Telepalliative care is an important component of this program where patients and their caregivers may have a virtual visit with any member of the team using their own smart phone or laptop computer. About $20 \%$ of patients utilize the telemedicine service. The nurses may also receive physician support via telemedicine while in the patient's home. Patients have access to coverage $24 / 7$ by telephone or telemedicine to one of the program physicians. The program also supports 12 volunteers who visit patients and are considered members of the palliative care team. Along with being "good listeners," those with specific expertise provide Reiki therapy or play musical instruments for patients. The volunteers are college students or members of the local community and are trained by the social worker.

Patients eligible for the HBPC program include homebound frail elders, patients with advanced heart failure, chronic obstructive pulmonary disease (COPD) on home oxygen, metastatic cancer, or severe dementia. Patients are excluded if they live in a skilled nursing facility or have addiction and behavioral health issues. Eligible patients are identified with an algorithm developed by the ACO using CMS medical claims data (e.g., costliest 5\%, Hierarchical Condition Categories, two hospital admissions or ER visits in prior 12 months, the ordering of a hospital bed, walker, or home oxygen). The primary care physician is notified that their patient is eligible for HBPC and they may opt out; this occurs in $<5 \%$ of cases. Patients are contacted by phone for program enrollment and further screened during the initial nurse home visit. Patients sign consent for HBPC and no one refused program enrollment during this study period. This HBPC program provides many elements of traditional home-based primary care and case management programs such as nurse home visits, but differs in the provision of 24/7 coverage, team-based care, use of telemedicine, and specialty level palliative care. ${ }^{8-11}$

\section{Patient identification}

There are 28,566 MSSP ACO patients at ProHEALTH located primarily in the five boroughs of New York City and Long Island. For this study population, only patients living in Queens, Nassau, and Suffolk Counties with 12 months of continuous Medicare claims data before death were included. This study included 651 MSSP ACO patients who died between October 1, 2014, and March 31, 2016. There were 82 decedents enrolled in HBPC compared to 569 who died with usual care (Table 1). Both groups comprised $98 \%$ fee for service Medicare and 2\% dual eligible with Medicaid. Although the HBPC team cared for 975 patients from the MSSP ACO and other health plans during this period, only the 82 MSSP ACO decedents were included in this study. 


\begin{tabular}{|c|c|c|c|}
\hline Characteristic & $\begin{array}{l}\text { Control } \\
\text { group } \\
(\mathrm{N}=569)\end{array}$ & $\begin{array}{l}\text { Home-based } \\
\text { palliative } \\
\text { care }(\mathrm{N}=82)\end{array}$ & $\mathrm{p}$ \\
\hline Race: white & $92 \%$ & $95 \%$ & 0.5287 \\
\hline Male & $287(50 \%)$ & $38(46 \%)$ & 0.4902 \\
\hline Female & $282(50 \%)$ & $44(54 \%)$ & 0.4902 \\
\hline \multicolumn{4}{|l|}{ Age (years) } \\
\hline Mean & 85 & 90 & $<0.0001$ \\
\hline Median & 86 & 91 & NA \\
\hline \multicolumn{4}{|c|}{ Charlson comorbidity index } \\
\hline Mean & 7.98 & 7.83 & 0.4321 \\
\hline Median & 8 & 8 & N/A \\
\hline Cancer diagnosis & $313(55 \%)$ & $47(57 \%)$ & 0.6965 \\
\hline \multicolumn{4}{|c|}{ Home-based palliative care LOS (days) } \\
\hline Mean & NA & 109 & NA \\
\hline Median & & 56 & \\
\hline
\end{tabular}

LOS, length of stay.

\section{Measures}

Total Medicare Part A (inpatient hospital, emergency room, hospice, home health services), Part B (outpatient, medical), and Part D (pharmaceutical) costs, resource utilization, and patient demographic and clinical data were collected for all patients who died during this 18-month study period. Total cost of care, ER utilization, hospital admission rate, hospice utilization, and length of stay (LOS) were quantified. Total care costs were defined as the sum of Medicare Parts A, B, and D claims. A Charlson comorbidity index (CCI) was used to evaluate disease burden and mortality risk. The CCI was calculated for each patient from the Medicare claims data designating a point value for each of 22 conditions obtained from ICD-10 codes. ${ }^{12}$

\section{Statistical analyses}

For comparing patient cost differences between those enrolled in HBPC versus usual care, a two-sample Welch $t$ test was used as the primary comparisons test. A square root transformation was applied to patient cost, to account for skewness and fulfilling the assumption that the analyzed data follow a normal distribution pattern. Patient cost data are commonly positive or right skewed. The Welch $t$ test is used for data that are unpaired, where two populations have unequal sample sizes and variance. Median cost metrics were also compared using the Wilcoxon rank-sum test. This is a nonparametric standard test for comparing metrics, where those metrics are not required to be derived from a particular distribution, like a normal distribution. This approach is commonly used to compare measures such as medians.

The Z-test of proportions was used for comparing rates between two groups, and if that difference is statistical significance. This approach can be used with sample sizes that are reasonably large, where rate data are believed to converge to a normal distribution. This test was used to compare the rate metric of hospice utilization.

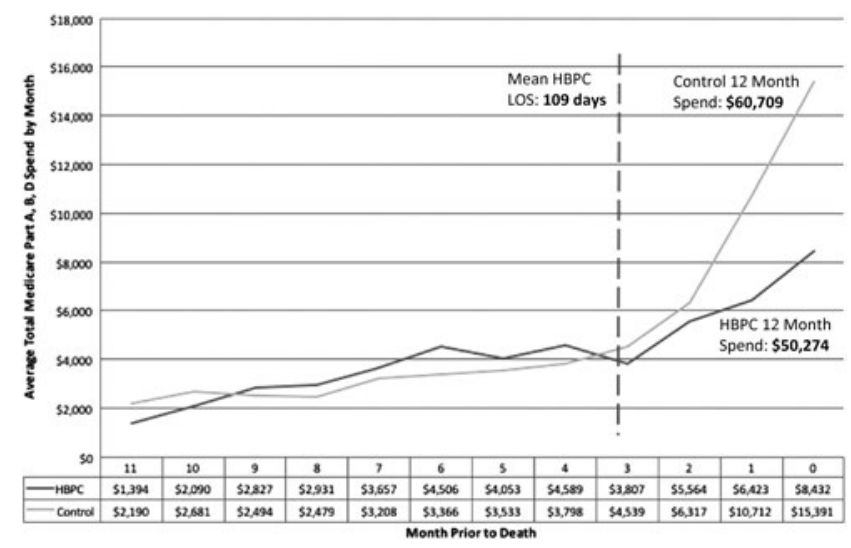

FIG. 1. Average Medicare Part A, B, D spending by month before death (home-based palliative care vs. control).

\section{Results}

Cost per patient for Medicare parts A, B, and D in the final year of life was $\$ 10,435$ lower for those receiving $\mathrm{HBPC}$ compared to usual care (Fig. 1). The cost per patient during the final three months of life was $\$ 12,000$ lower with HBPC than for usual care $(\$ 20,420$ vs. $\$ 32,420 ; p=0.0002)$; largely driven by a $35 \%$ reduction in Medicare Part A with HBPC compared to controls ( $\$ 16,892$ vs. $\$ 26,171 ; p=0.0037$ ). HBPC also resulted in a $37 \%$ reduction in Medicare Part B cost during the final three months of life compared to usual care $(\$ 3,114$ vs. $\$ 4913 ; p=0.0008)$. There was no significant difference in Medicare Part D (pharmaceuticals) cost between the two groups (Table 2).

Hospital admissions were reduced by $34 \%$ in the final month of life for patients enrolled in HBPC. The number of admissions per 1000 beneficiaries per year was 3073 with HBPC and 4640 with usual care $(p=0.0221)$. HBPC was also associated with a trend toward reduced ER visits per 1000 beneficiaries compared to usual care, 878 vs. 1097. HBPC resulted in a $35 \%$ increase $(p=0.0005)$ in hospice utilization rate and a significantly longer median hospice LOS compared to controls (34 days vs. 10 days; $p<0.0001$ ). Mean hospice LOS was also longer in the HBPC group compared to controls (47 days vs. 23 days; $p=0.0003$ ) (Table 3 ).

\section{Discussion}

HBPC was associated with significant reductions in total Medicare cost, fewer hospital admissions, and an increase in hospice utilization in the final months of life. There was a $45 \%$ reduction in cost for the final month of life with $\mathrm{HBPC}$. These results are likely due, in part, to the fact that HBPC was also associated with a very high likelihood of death at home (87\%). This is an especially important outcome measure since nationally only $24 \%$ of Medicare beneficiaries die at home with usual care. ${ }^{13}$

The return on investment for HBPC depends on financial alignment with payers and providers; a unique opportunity that occurs within an ACO where high-value care, rather than care intensity, is financially rewarded. CMS announced that $50 \%$ of payment will be value based by the end of $2018 .{ }^{14}$ Other payer-provider partnerships have already noticed the value proposition for HBPC and developed programs of their own. ${ }^{15}$ 
Table 2. Total Average Medicare Part A, B, and D Spending By Month Before Death:

Home-Based Palliative Care Versus Control Group

\begin{tabular}{ccc}
$\begin{array}{c}\text { Control } \\
\text { group } \\
(\mathrm{N}=569)\end{array}$ & $\begin{array}{c}\text { Home-based } \\
\text { palliative } \\
\text { care }(\mathrm{N}=82)\end{array} \quad \mathrm{p}$ \\
\hline
\end{tabular}

Average Part A, B, and D spending by month

before death

Month of death

(Month 0)

Month 1

Month 2

Last three months

Month 3

Month 4

Month 5

$\$ 15,391$

$\$ 8,432$

$\$ 10,712$

$\$ 6,317$

$\$ 6,423$

$\$ 32,420$

$\$ 4,539$

$\$ 3,799$

$\$ 3,533$

Last six months

$\$ 44,291$

Month 6

Month 7

$\$ 3,366$

$\$ 3,208$

Month 8

$\$ 2,479$

$\$ 2,494$

$\$ 2,681$

Month 10

$\$ 2,190$

Month 11

$\$ 60,709$

$\$ 5,564$

$\$ 20,420$

$\$ 3,807$

$\$ 4,589$

$\$ 4,053$

$\$ 32,869$

$\$ 4,506$

$\$ 3,657$

$\$ 2,931$

$\$ 2,827$

$\$ 2,090$

$\$ 1,394$

$\$ 50,274$

0.0002

0.0154

0.8025

0.0002

0.8025

0.0271

0.0525

0.0207

0.2097

0.4617

0.3094

0.1958

0.5337

0.2163

0.1729

Average Part A spending by month before death

Month of death \$13,315 \$7,492 (Month 0)

Month 1

Month 2

$\$ 8,180$

Last three months

$\$ 4,676$

$\$ 5,103$

$\$ 26,171$

Month 3

$\$ 3,229$

$\$ 4,298$

Month 4

$\$ 2,746$

$\$ 2,419$

Month 5

$\$ 34,565$

$\$ 2,259$

Month 6

$\$ 2,139$

$\$ 1,600$

$\$ 1,570$

Month 8

$\$ 1,731$

$\$ 1,305$

Month 10

$\$ 45,170$

$\$ 16,892$

$\$ 2,863$

$\$ 3,214$

$\$ 2,760$

$\$ 25,729$

$\$ 3,282$

$\$ 2,580$

$\$ 1,842$

$\$ 1,748$

$\$ 1,337$

$\$ 423$

Month 11

$\$ 36,941$

Average Part B spending by month before death

Month of death $\quad \$ 1,508 \quad \$ 816$ (Month \#0)

$\begin{array}{lrr}\text { Month 1 } & \$ 2,062 & \$ 1,194 \\ \text { Month 2 } & \$ 1,343 & \$ 1,104 \\ \text { Last three months } & \$ 4,913 & \$ 3,114 \\ \text { Month 3 } & \$ 1,074 & \$ 829 \\ \text { Month 4 } & \$ 835 & \$ 1,249 \\ \text { Month 5 } & \$ 916 & \$ 1,175 \\ \text { Last six months } & \$ 7,743 & \$ 6,367 \\ \text { Month 6 } & \$ 920 & \$ 1,070 \\ \text { Month 7 } & \$ 872 & \$ 952 \\ \text { Month 8 } & \$ 723 & \$ 951 \\ \text { Month 9 } & \$ 764 & \$ 913 \\ \text { Month 10 } & \$ 798 & \$ 650 \\ \text { Month 11 } & \$ 733 & \$ 697 \\ \text { Last 12 months } & \$ 12,548 & \$ 11,599\end{array}$

Average Part D spending by month before death

Month of death $\quad \$ 27 \quad \$ 22$ (Month 0)

Month 1

$\$ 96$

Month 2

$\$ 79$

$\$ 49$

$\$ 96$

0.3244

0.6686

0.1323

(continued)
TABLE 2. (CONTINUED)

\begin{tabular}{lrrr}
\hline & $\begin{array}{c}\text { Control } \\
\text { group } \\
(\mathrm{N}=569)\end{array}$ & $\begin{array}{c}\text { Home-based } \\
\text { palliative } \\
\text { care }(\mathrm{N}=82)\end{array}$ & $\mathrm{p}$ \\
\hline Last three months & $\$ 203$ & $\$ 167$ & 0.9148 \\
Month 3 & $\$ 79$ & $\$ 70$ & 0.6154 \\
Month 4 & $\$ 87$ & $\$ 71$ & 0.9729 \\
Month 5 & $\$ 73$ & $\$ 69$ & 0.3847 \\
Last six months & $\$ 442$ & $\$ 377$ & 0.9839 \\
Month 6 & $\$ 75$ & $\$ 100$ & 0.1285 \\
Month 7 & $\$ 88$ & $\$ 82$ & 0.3900 \\
Month 8 & $\$ 71$ & $\$ 103$ & 0.1967 \\
Month 9 & $\$ 74$ & $\$ 132$ & 0.2314 \\
Month 10 & $\$ 60$ & $\$ 79$ & 0.2412 \\
Month 11 & $\$ 79$ & $\$ 261$ & 0.0830 \\
Last 12 months & $\$ 889$ & $\$ 1,134$ & 0.1896 \\
\hline
\end{tabular}

A Cochrane review ${ }^{16}$ evaluated the cost savings of HBPC for people with advanced illness. On the basis of 23 studies, including 37,561 patients and 4042 family caregivers, when a patient receives $\mathrm{HBPC}$, the chances of dying at home more than doubles. This Cochrane review identified only six studies addressing cost-effectiveness of HBPC, with two showing cost savings. One such prospective randomized trial of 52 patients with multiple sclerosis in London demonstrated a significant cost reduction within 12 weeks postenrollment. 17

Some HBPC programs have demonstrated value with the formation of payer-provider partnerships. ${ }^{18}$ Kerr et al. showed a \$6,804 PMPM cost of care with HBPC versus $\$ 10,712$ for usual care in the final three months of life. Their HBPC program was implemented through a hospice program and commercial insurance provider in New York. ${ }^{19}$ At one month before death, the PMPM cost was $\$ 7,170$ for HBPC recipients compared to $\$ 13,440$ for controls. This program also demonstrated increased hospice enrollment (70\% vs. $25 \%$ ) and longer median hospice LOS (34 days vs. 9 days) compared to usual care.

The Sutter Health Advanced Illness (AIM) Program ${ }^{20}$ is a HBPC program in northern California that enrolled patients with a prognosis of less than one year who met Medicare eligibility criteria for home health and were continuing treatment for their illness. Patients enrolled in this program had $63 \%$ fewer hospitalizations compared to pre-enrollment. The associated cost savings was estimated to be $\$ 2,000$ PMPM. A Kaiser Permanente HBPC program for cancer, heart failure, or COPD patients delivered in health maintenance organizations in Hawaii and Colorado demonstrated improved patient satisfaction, increased likelihood of dying at home, and a $33 \%$ overall cost savings. ${ }^{21}$ The OACIS program in Pennsylvania demonstrated fewer hospital admissions and a lower 30-day readmission rate with their HBPC program but no impact on ER visits. ${ }^{22}$

Key elements of successful programs appear to be homebased care, in person interactions, geriatric assessment, caregiver support, palliative care skills, and round the clock clinical availability. The remote delivery of telephone-only care coordination has demonstrated modest success. A nurse practitioner once a year in home visit program delivered by a health plan demonstrated a $14 \%$ reduction in hospital 
Table 3. Hospital Admissions, Emergency Room Visits, and Hospice Utilization

\begin{tabular}{|c|c|c|c|}
\hline Outcomes & $\begin{array}{l}\text { Control group } \\
\qquad(\mathrm{N}=569)\end{array}$ & $\begin{array}{l}\text { Home-based palliative } \\
\text { care }(\mathrm{N}=82)\end{array}$ & $\mathrm{p}$ \\
\hline Hospital admissions/1000 patients in final month of life & 4634 & 3073 & 0.0221 \\
\hline ER visits/1000 patients in final month of life & 1097 & 878 & 0.5882 \\
\hline \multicolumn{4}{|l|}{ Hospice utilization } \\
\hline - Enrollment rate & $211 / 569(37 \%)$ & $47 / 82(57 \%)$ & 0.0005 \\
\hline - Mean LOS & 23 & 47 & 0.0003 \\
\hline - Median LOS & 10 & 34 & $<0.0001$ \\
\hline
\end{tabular}

${ }^{a}$ Long-term care resident hospice outliers with LOS $>180$ days removed from control group $(n=8)$.

admissions in a Medicare population, largely through increased hospice referrals. ${ }^{23}$ Another program using telephonic advance care planning for Medicare Advantage members demonstrated a cost savings of $\$ 13,956$ per decedent in the final six months of life compared to controls. ${ }^{24}$

Improving value by increasing quality and reducing cost is one of the goals of ACOs. ${ }^{25}$ Failure or late referral of terminally ill patients to hospice results in costly care that is often discordant with patient preferences. Physician factors, rather than patient preferences, correlate most with hospice referral rate. ${ }^{26}$ Our HBPC program achieved an $87 \%$ at home death rate through timely referral to hospice for eligible patients and home palliative care for those patients who declined enrollment or deemed ineligible for hospice care due to ongoing treatments or lack of a hospice diagnosis. In our study, $57 \%$ of decedents were referred to hospice. Unlike a Medicare Advantage program, costs incurred during hospice care are included in Medicare Part A and attributed to the MSSP ACO total cost of care. Despite the inclusion of hospice care, these services cost significantly less than usual care, which often results in unwanted hospitalizations. One study noted a cost reduction of $\$ 6,430$ per patient enrolled in hospice care for 15 to 30 days. $^{27}$

\section{Clinical scenario}

Mrs. M wants to stay in her home. She has hired private home health aides to assist her. There is a plan for the treatment of her heart failure and shortness of breath should things get worse. A MOLST form stating her two preferences (i.e., DNR and no future hospitalization) is tucked away in a white envelope taped to the side of the refrigerator. She no longer takes 16 pills a day. She knows in the future she could transition to a hospice program if she becomes eligible. When she calls the HBPC 24/7 number, she knows someone will answer the phone. They will not say "If this is an emergency, go to your nearest emergency room."

One limitation of this study is the lack of minority populations and Medicaid. Another limitation is the lack of a case matched control group, although the CCI was used to quantify disease burden, which was equal for both groups $(p=0.4321)$. In addition, all patients in both groups had fee for service Medicare, died during the same 18-month study period, used the same ACO physicians, and lived in Queens, Nassau, or Suffolk Counties in New York. There was no difference in race, age, or gender between groups.

CMS provides all beneficiary claims data and ICD-10 codes to MSSP ACOs. Identifying patients likely to benefit from HBPC based on historical claims is challenging since spending patterns are variable and do not reliably predict palliative care needs. ${ }^{28}$ Predictors of palliative care need may include prognosis of less than one year, frailty, functional decline, and social isolation, which are not readily available through claims. Our claim-based algorithm appears to correctly identify a cohort of beneficiaries with a $57 \%$ risk of death within six months; however, we were unable to serve them all due to staffing limitations. In fact, only $13 \%$ of the MSSP ACO decedents were enrolled in HBPC. The mean LOS in HBPC was 109 days leading us to wonder if even better outcomes might result from earlier enrollment. These positive findings are fueling additional growth with the hiring of new staff to better meet the palliative needs of all our seriously ill ACO patients.

The Medicare Hospital Insurance Trust Fund, which pays Part A benefits, is expected to run out by $2028 .^{29}$ The Trust Fund is financed primarily through payroll tax. As more baby boomers reach Medicare eligibility age, a declining workforce will be making payroll contributions to the Fund. Trust Fund solvency depends on reducing healthcare costs. We showed that average Part A cost per decedent was $\$ 9,279$ lower with HBPC compared to usual care. Providing access to palliative care to the sickest $2 \%$ of the 55.3 million Medicare beneficiaries in the United States could result in better outcomes at substantially lower cost. New reimbursement models are required for reliable team-based, technologyenhanced models of HBPC. The perfect alignment of quality and financial outcomes in an ACO provides a unique opportunity to support HBPC.

\section{Author Disclosure Statement}

David Cooper owns shares in United Health Group. Dana Lustbader, James Mittelberger, Mitchell Mudra, Carole Romano, Ed Lukoski, Andy Chang, Terry Scherr have nothing to disclose.

\section{References}

1. Institute of Medicine: Dying in America: Improving Quality and Honoring Individual Preferences Near the End of Life. Report Brief. 2015. Washington, DC: The National Academies Press. www.nap.edu/read/18748/chapter/1 (Last accessed July 16, 2016).

2. May P, Normand C, Morrison RS: Economic impact of hospital inpatient palliative care consultation: Review of current evidence and directions for future research. J Palliat Med 2014;17:1054-1063.

3. Smith TJ, Cassel JB: Cost and non-clinical outcomes of palliative care. J Pain Symptom Manage 2009;38:32-44. 
4. Morrison RS, Dietrich J, Ladwig S, et al.: Palliative care consultation teams cut hospital costs for Medicaid beneficiaries. Health Aff (Millwood) 2011;30:454-463.

5. Rabow M, Kvale E, Barbour L, et al.: Moving upstream: A review of the evidence of the impact of outpatient palliative care. J Palliat Med 2013;12:1540-1549.

6. Gill TM, Gahbauer EA, Han L, et al.: The role of intervening hospital admissions on trajectories of disability in the last year of life: Prospective cohort study of older people. BMJ 2015;350:h2361.

7. Bernacki RE, Block SD: Communication about serious illness care goals. A review and synthesis of best practices. JAMA Intern Med 2014;174:1994-2003.

8. Edes T, Kinosian B, Vuckovic N, et al.: Better access, quality, and cost for clinically complex veterans with homebased primary care. J Am Geriatr Soc 2014;62:1954-1961.

9. Jonge KE, Jamshed N, Gilden D, et al.: Effects of homebased primary care on Medicare costs in high-risk elders. J Am Geriatr Soc 2014;62:1825-1831.

10. Boling BA, Leff B: Comprehensive longitudinal health care in the home for high cost beneficiaries: A critical strategy for population health management. J Am Geriatr Soc 2014;62:1974-1976.

11. Casarett D, Teno J: Why population health and palliative care need each other. JAMA 2016;316:27-28.

12. Deyo RA, Cherkin DC, Ciol MA: Adapting a clinical comorbidity index for use with ICD-9-CM administrative databases. J Clin Epidemiol 1992;45:613-619.

13. Health, United States, 2010: with special feature on death and dying. National Center for Health Statistics. www.cdc. gov/nchs/data/hus/hus10.pdf (Last accessed June 7, 2016).

14. Centers for Medicare and Medicaid Services (CMS). Hospital value-based purchasing. 2015. www.hhs.gov/about/news/2015/ 01/26/better-smarter-healthier-in-historic-announcement-hhssets-clear-goals-and-timeline-for-shifting-medicare-reimburse ments-from-volume-to-value.html (Last accessed June 1, 2016).

15. Center to Advance Palliative Care: Improving the care of serious illness though innovative payer-provider partnerships: A palliative care toolkit and resource guide. www. capc.org/payers/palliative-care-payer-provider-toolkit (Last accessed June 1, 2016).

16. Gomes B, Calanzani N, Curiale V, et al.: Effectiveness and cost-effectiveness of home palliative care services for adults with advanced illness and their caregivers. Cochrane Database of Syst Rev 2013;(6):CD007760.

17. Higginson IJ, McCrone P, Hart SR, et al.: In short term palliative care cost effective in multiple sclerosis? A randomized phase II trial. J Pain Symptom Manage 2009;38: 816-826.

18. Meyer H: Changing the conversation in California about care near the end of life. Health Aff (Millwood) 2011;30: 390-393.
19. Kerr CW, Donohue KA, Tangeman JC, et al.: Cost savings and enhanced hospice enrollment with a home based palliative care program implemented as a hospice-private payer partnership. J Palliative Med 2014;17:1328-1335.

20. Meyer H: Innovation profile: Changing the conversation in California about care near the end of life. Health Aff (Millwood) 2011;30:390-393.

21. Brumley R, Enguidanos S, Jamison P, et al.: Increased satisfaction with care and lower costs: Results of a randomized trial of in home palliative care. J Am Geriatr Soc 2007;55:993-1000.

22. Lukas L, Foltz C, Paxton H: Hospital outcomes for a home based palliative medicine consulting service. J Palliat Med 2013;16:1-6.

23. Mattke S, Han D, Wilks A, Sloss E: Medicare home visit program associated with fewer hospital and nursing home admissions increased office visits. Health Aff (Millwood) 2015;34:2138-2146.

24. Colaberdine V, Marshall C, DuBose P, et al.: Economic impact of an advanced illness consultation program within a Medicare Advantage plan population. J Palliat Med 2016; 19:1-4.

25. Smith G, Bernacki R, Block S: The role of palliative care in population management and accountable organizations. J Palliat Med 2015;18:486-494.

26. Obermeyer Z, Powers B, Maker M, et al.: Physician characteristics strongly predict patient enrollment in hospice. Health Aff (Millwood) 2015;34:993-1000.

27. Kelley AS, Deb P, Du Q, et al.: Hospice enrollment saves money for Medicare and improves care quality across a number of different lengths-of-stay. Health Aff (Millwood) 2013;32:552-561.

28. Davis, MA, Nallamothu BK, Banerjee M, et al.: Identification of four unique spending patterns among older adults in the last year of life challenges standard assumptions. Health Aff (Millwood) 2016;35:1-8.

29. Medicare Trustee Report: 2016 Annual Report of the Board of Trustees of the Federal Hospital Insurance and Federal Supplementary Medical Insurance Trust Funds. www.cms.gov/ Research-Statistics-Data-and-Systems/Statistics-Trends-andReports/ReportsTrustFunds/Downloads/TR2016.pdf (Last accessed July 16, 2016).

Address correspondence to: Dana Lustbader, MD, FAAHPM Department of Palliative Care ProHEALTH Care Associates, LLP 2800 Marcus Avenue Suite 205 Lake Success, NY 11042

E-mail: DanaLustbader@iCloud.com 